\title{
UM PASSADO RURAL NUM PRESENTE URBANO: A REPRESENTAÇÃO DAS FESTAS JUNINAS NA IMPRENSA PERNAMBUCANA
}

\author{
Mário Ribeiro dos Santos ${ }^{1}$
}

\begin{abstract}
Resumo: Este artigo tem como objetivo analisar a forma como a imprensa pernambucana representava as festas juninas num período consagrado pela historiografia como República "Velha", mais precisamente nas primeiras décadas do século XX. A intenção é analisar quais os caminhos percorridos pelos profissionais das letras para divulgação da festa na capital do estado, visando compreender quem era o seu público de leitores, se havia mais de um perfil de consumidor e quais os efeitos de sentido provocados na sociedade após o consumo das manchetes e das notícias diárias. A análise da documentação coletada nos dois principais centros de documentação do Estado - o Arquivo Público Estadual Jordão Emerenciano (APEJE) e a Fundação Joaquim Nabuco (Fundaj) -, nos leva a perceber que os símbolos comuns à festa (balões, fogos de artifício, fogueiras, livros de sorte, comidas de milho), transitam no intervalo de tempo pesquisado, sem necessariamente serem apresentados de forma evolutiva e exclusivamente locais; pelo contrário, sendo incorporados à imagem nacional da festa (do litoral ao interior) e convivendo com as novas tendências criadas pelos deslocamentos da História. De maneira geral, podemos inferir que tais representações constroem elos com o passado rural, transfigurando o cenário urbano da festa com símbolos e personagens que remetem à vida nas fazendas e nos engenhos, difundindo traduções de pensamentos, opiniões, imagens e visões sobre como as festas juninas são e devem acontecer.
\end{abstract}

Palavras-chave: Festas juninas. Representações. Imprensa pernambucana.

\section{A RURAL PAST ON AN URBAN PRESENT: THE REPRESENTATION OF JUNE PARTIES ON THE PERNAMBUCAN PRESS}

\begin{abstract}
This article aims to analyze the way the Pernambuco press represented the June festivities in a period consecrated by historiography as "Old" Republic, more precisely in the first decades of the twentieth century. The intention is to analyze the paths taken by the letter professionals to publicize the party in the state capital, in order to understand who their readers were, if there was more than one consumer profile and what the effects of meaning caused on society after the event, consumption of headlines and daily news. The analysis of the documentation collected at the two main state documentation centers - the Jordão Emerenciano State Public Archive (APEJE) and the Joaquim Nabuco Foundation (Fundaj) - leads us to realize that the symbols common to the party (balloons, fireworks, bonfires, lucky books, corn meals), transit in the researched time interval, without necessarily being presented in an evolutionary and exclusively local way; on the contrary, being incorporated into the national image of the festival (from the coast to the interior) and living with the new trends created by the displacements of History. In general, we can infer that such representations build links with the rural past, transfiguring the urban scene of the party with symbols and characters that refer to life on farms and mills, spreading translations of thoughts, opinions, images and visions about how parties juninas are and should happen.
\end{abstract}

Keywords: June parties. Representations. Pernambuco press.

\section{UN PASSÉ RURAL DANS UN PRÉSENT URBAIN: LA REPRÉSENTATION DES PARTIS DE JUIN SUR LA PRESSE PERNAMBUCAN}

\footnotetext{
${ }^{1}$ Professor Adjunto da Universidade de Pernambuco Campus Mata Norte, onde leciona as disciplinas: História da África, Educação das Relações Étnico-Raciais, Cultura Negra e Ensino de História, na Graduação. No ProfHistória ministra a disciplina Ensino de História da África e da Cultura AfroBrasileira. Possui Doutorado em História pela Universidade Federal de Pernambuco (UFPE).
}

Revista Escritas do Tempo - v. 1, n. 2, jul-out/2019 - p. 52-74 
Résumé: Cet article a pour objectif d'analyser la manière dont la presse pernambuco a représenté les festivités de juin à une époque consacrée par l'historiographie en tant que «vieille» République, plus précisément au cours des premières décennies du XXe siècle. L'intention est d'analyser les parcours empruntés par les professionnels du courrier pour faire connaître le parti dans la capitale nationale, afin de comprendre qui étaient leurs lecteurs, s'il existait plus d'un profil de consommateur et quels étaient les effets du sens sur la société après l'événement. consommation des titres et des nouvelles quotidiennes. L'analyse de la documentation réunie dans les deux principaux centres de documentation de l'Etat - les Archives publiques de Jordão Emerenciano (APEJE) et la Fondation Joaquim Nabuco (Fundaj) - nous amène à comprendre que les symboles communs au parti (ballons, feux d'artifice, feux de joie, livres porte-bonheur, repas de maïs), transit dans l'intervalle de temps recherché, sans nécessairement être présenté de manière évolutive et exclusivement locale; au contraire, être intégré dans l'image nationale du festival (de la côte à l'intérieur) et vivre avec les nouvelles tendances créées par les déplacements de l'Histoire. En général, on peut en déduire que ces représentations établissent des liens avec le passé rural, transfigurant la scène urbaine du parti avec des symboles et des caractères faisant référence à la vie dans les fermes et les moulins, diffusant des traductions de pensées, d'opinions, d'images et de visions sur la les juninas sont et devraient arriver.

Mots-clés: Soirées de juin. Représentations Presse pernambouc.

\section{UN PASADO RURAL EN UN PRESENTE URBANO: LA REPRESENTACIÓN DE LAS PARTES DE JUNIO EN LA PRENSA PERNAMBUCANA}

Resumen: Este artículo tiene como objetivo analizar la forma en que la prensa de Pernambuco representó las festividades de junio en un período consagrado por la historiografía como la "Antigua" República, más precisamente en las primeras décadas del siglo XX. La intención es analizar los caminos tomados por los profesionales de la carta para publicitar la fiesta en la capital del estado, con el fin de comprender quiénes eran sus lectores, si había más de un perfil de consumidor y cuáles fueron los efectos del significado que causaron en la sociedad después del evento consumo de titulares y noticias diarias. El análisis de la documentación recopilada en los dos principales centros de documentación estatales: el Archivo Público del Estado Jordão Emerenciano (APEJE) y la Fundación Joaquim Nabuco (Fundaj), nos lleva a darnos cuenta de que los símbolos comunes a la fiesta (globos, fuegos artificiales, hogueras, libros de la suerte, harinas de maíz), tránsito en el intervalo de tiempo investigado, sin necesariamente ser presentado de una manera evolutiva y exclusivamente local; por el contrario, incorporarse a la imagen nacional del festival (desde la costa hasta el interior) y convivir con las nuevas tendencias creadas por los desplazamientos de la Historia. En general, podemos inferir que estas representaciones construyen vínculos con el pasado rural, transfigurando la escena urbana de la fiesta con símbolos y personajes que se refieren a la vida en granjas y molinos, difundiendo traducciones de pensamientos, opiniones, imágenes y visiones sobre cómo las fiestas Las juninas son y deberían suceder.

Palabras claves: Fiestas de junio. Representaciones. Prensa Pernambuco.

\section{Introdução}

A imprensa pernambucana nas primeiras décadas do século passado constitui um amplo canal para se pensar as representações das festas juninas no tempo. Um leque de periódicos circulava em Recife no período em análise, formado por um time de intelectuais que transitavam entre os corredores das Faculdades de Direito e Medicina, e as redações dos jornais Diário de Pernambuco, Jornal do Recife, A Província, A Noite, A Rua, A Notícia, Jornal Pequeno, Diario do Estado, O Intransigente, Jornal do 
Commercio, Diário da Manhã, Diário da Tarde, A Tribuna, entre outros. Uns formando um bloco de opiniões mais conservadoras; outros com pensamentos mais ousados e ideias inovadoras (BARROS, 1972).

Nesse contexto, os veículos Diário de Pernambuco, Jornal do Recife, A Província e a Folha do Norte constituíam o que o pesquisador Souza Barros chama de "imprensa de classe", formada por interesses conservadores, escrita por bacharéis, na sua maioria filhos dos donos de terra, provenientes da agricultura da cana (BARROS, 1972). Para o presente estudo, os jornais Diário de Pernambuco, Jornal do Recife, Jornal Pequeno e Folha da Manhã traziam com mais frequência notícias sobre as festas juninas, mesmo que apresentadas com um enfoque maior nos divertimentos da elite, apresentando alguns indícios nos modos de celebração das camadas populares. Importante destacar que nem todos os periódicos que circulavam no período estudado encontram-se nos arquivos e mesmo aqueles digitalizados, não apresentam todos os números arquivados.

Identificamos, no decorrer da pesquisa, um tipo de imprensa que abre espaço para um cenário de notícias fora das fronteiras do Estado, dando maior atenção às agitações revolucionárias, aos movimentos sindicais e às novidades do cotidiano. É nesse sentido que as crônicas sociais de algumas revistas, entre elas A Pilhéria, Pra Você e Revista da Cidade ganham destaque no trabalho. Outros periódicos com esse formato também circulavam no estado - Avança!, A Noite, Semana Ilustrada, Alvorada, Estudantina, entre outros -, mas nem todas as coleções estavam completas. Os números que estavam disponíveis para consulta não atendiam ao que procurávamos.

Diante do conjunto das evidências reunidas, o foco da narrativa deteve-se nas informações que a documentação trazia sobre a festa. $\mathrm{O}$ trabalho consistiu, basicamente, em exercitar o olhar para o que estava escrito, a forma como se escrevia, para quem se escrevia, considerando a imprensa como um veículo de expressão da "mentalidade de um período, um lugar onde a sociedade discutia seus caminhos e se representava" (RABELLO, 2004, p. 6).

Numa passagem pela documentação coletada, percebemos que os símbolos comuns à festa (balões, fogos de artifício, fogueiras, livros de sorte, comidas de milho), transitam no intervalo de tempo pesquisado, sem necessariamente serem apresentados de forma evolutiva e exclusivamente locais. Pelo contrário, estavam incorporados à imagem nacional da festa (do litoral ao interior) e conviviam com as novas tendências criadas pelos deslocamentos da História.

Revista Escritas do Tempo - v. 1, n. 2, jul-out/2019 - p. 52-74 
Apesar de não existir periódicos e cronistas especializados em escrever sobre as festividades sanjoanescas (como encontramos sobre o Carnaval $^{2}$ ), a documentação investigada revela como alguns grupos sociais do Recife viviam e se organizavam no seu cotidiano, preparando-se para as comemorações juninas (SANTOS, 2010). Uma maneira diferente de "visitar a cidade nos seus detalhes, nos seus modos e modas" (REZENDE, 1997).

As notícias estimulavam o consumo dos produtos diretamente ligados à vivência da época, numa espécie de vitrine dos tempos modernos, invadindo a cidade e provocando o desejo de consumo de trajes finos e elegantes, dos eletrodomésticos (ferros de engomar, torradores de pão, aquecedores), dos novos fogões a gás "higiênicos e econômicos", das máquinas de escrever, entre outras novidades frutos das transformações nos modos e costumes trazidos pelo movimento acelerado da modernização.

Nas páginas dos jornais e revistas se faziam conhecer os calçados, os chapéus e as meias da Casa Ypiranga; os saldões de sapatos, exclusivamente no mês de junho, da sapataria Menandro. Para as mulheres, a dica da vez era usar o pó de arroz Cigana: "aderente, perfumado e amacia a pele", à venda nos principais armarinhos da cidade. $\mathrm{Na}$ Rua do Livramento, "as novidades de junho" da Casa Excelsior atraíam o que de mais "fino e moderno em calçados e chapéus" o Recife tinha para oferecer a sua "distinta clientela” (Revista A Pilhéria, 1925, n. 196, p. 32).

$\mathrm{O}$ anúncio continuava especificando o que estava em alta no momento e o que as senhoras, os senhores e as crianças poderiam usar nas ocasiões festivas de São João, como: os "finíssimos calçados de tiras de pelica em lindas combinações de duas cores. Sapatos de camurça preta, marrom e cinza em saltos mexicanos e Luiz XV. Meias de seda em cores e tipos de alta moda." Para os homens, recomendava-se os "calçados de luxo do afamado Polar, além dos chapéus de palha e meias de seda de todos os tipos e 'cores chics"'. Para as crianças, a indicação dos "sapatinhos, modelos da Casa Colombo do Rio de Janeiro e alpercatas de todos os feitios e cores", ganhava realce no anúncio (Revista A Pilhéria, 1925, n. 196, p. 32).

O comércio aproveitava a ocasião para incentivar a venda de tecidos, sapatos, lenços, chapéus e outros acessórios comuns à indumentária da época. Em geral, a

\footnotetext{
${ }^{2}$ A documentação sobre o Carnaval é vasta e diversificada nos arquivos do estado de Pernambuco. O APEJE disponibiliza ao público um conjunto de periódicos impressos pelas próprias agremiações na segunda metade do século XIX, a exemplo dos jornais O Corta Jaca, A Imprensa, entre outros que distribuídos entre os foliões dias antes da folia oficial.
} 
divulgação dos produtos aparecia ao lado de uma ilustração que remetia à celebração; situação que nos permite pensar no poder de persuasão dos anúncios. Eles comunicavam aos consumidores o que deveria ser usado, no sentido de integrar-se ao contexto da festa.

Outra importante estratégia da imprensa para estimular o consumo do São João pela sociedade era a divulgação diariamente, a partir do dia 1 de junho, da programação do período: as procissões organizadas pelas igrejas, os bailes e outros eventos que os clubes sociais e esportivos preparavam para celebrar o São João eram veiculados todos os dias. Até os anos 1920, era identificada uma certa frequência no número de notas de divulgação das procissões religiosas que aconteciam na cidade. A imprensa também dedicava dezenas de linhas na descrição dos detalhes da decoração e programação dos eventos, funcionando como convites aos devotos. Esses anúncios recebiam grande destaque nos jornais, mas a partir dos anos 1930, quando os festejos religiosos passaram a dividir, com maior realce, a programação da festa com as práticas profanas, quase não se identifica notas sobre as procissões.

No tocante aos bailes dançantes nos clubes sociais, a forma como a imprensa descrevia os pormenores dos eventos (decoração, tipo de traje, cardápio a ser servido, programação, entrega de brindes, presença de figuras ilustres, etc.) provocava o diferencial no sucesso de venda da bilheteria dos clubes, o que levava a diretoria a publicar notas comunicando aos associados com mensalidade atrasada a existência das últimas mesas.

A imprensa como mediadora de sentidos das festas juninas, através de uma linguagem persuasiva, seduzia os leitores, mobilizando-os e provocando um sentimento de consumo, que envolvia comportamentos e atitudes dos atores participantes, a ponto de nos permitir identificar como o acontecimento da festa modelava a vida da cidade (CERTEAU, 2008). Histórias de personagens foram reveladas, movimentando o cenário interno da festa, e detectando de perto a riqueza das suas partes, assim como as fissuras da sua estrutura.

\section{A imprensa e as representações que opõem o campo e a cidade}

Dois documentos se destacaram durante as pesquisas nos periódicos do início do século passado: a gravura de um matuto com a frase "Neste São João, o matuto é quem vem para a cidade. Eita Recife bão", publicada no jornal Pequeno, de 1905, e a coluna da revista A Pilhéria, edição de 1925, assinada pelo casal de matutos Filorenço e 
Frutunata, dois migrantes do campo espantados com os costumes da vida moderna na cidade (Figura 1 e Figura 2).

Figura 1: Guino, caricatura em crayon.

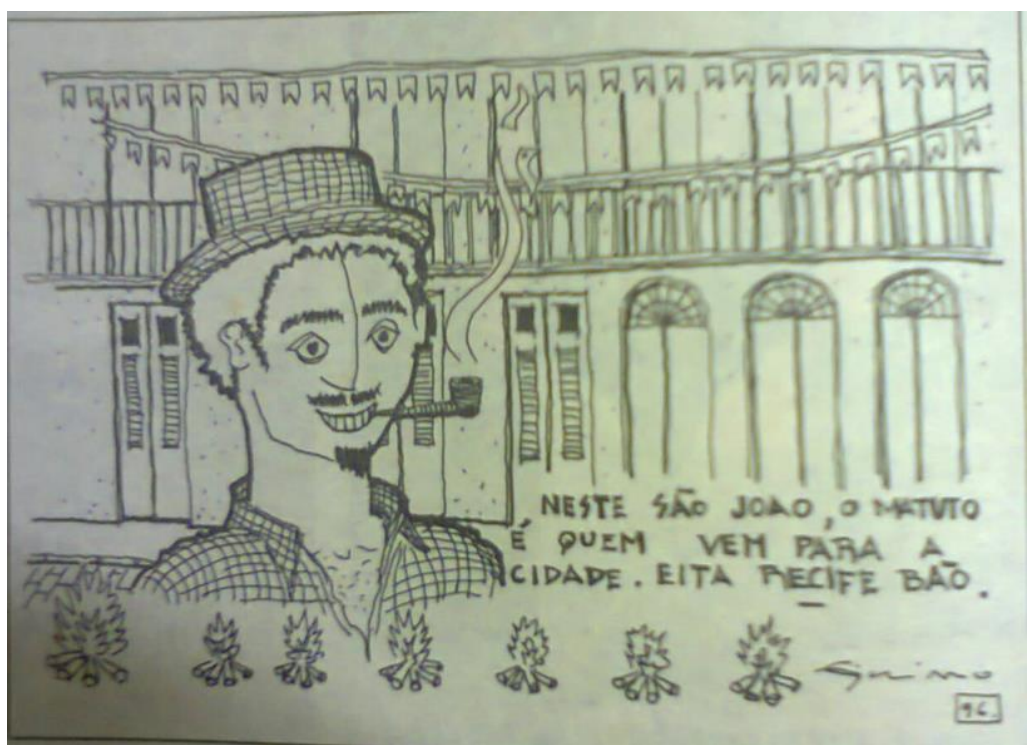

Fonte: Jornal Pequeno. Recife, 21 de junho de 1905.

Figura 2: O qui nós vê na capitá.

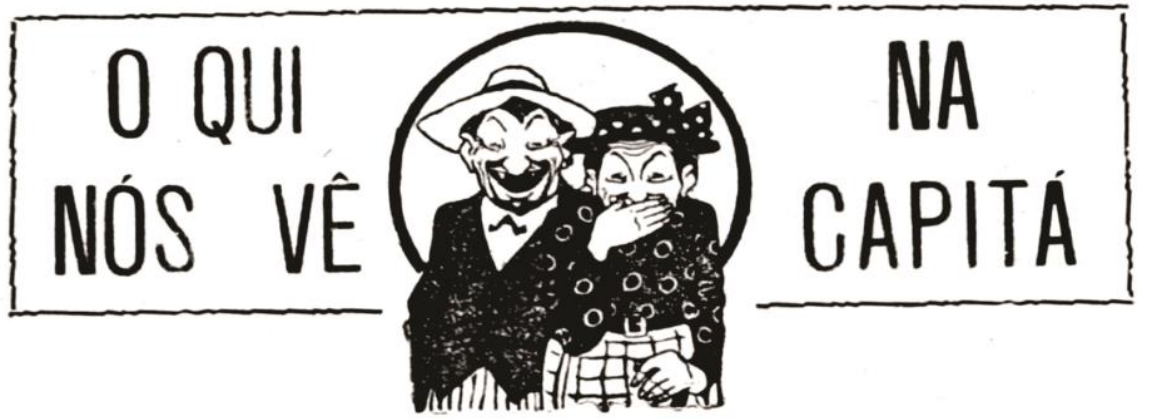

Fonte: Revista A Pilhéria, Recife, 1925, p. 20.

As imagens recorrentes na imprensa da época possibilitaram leituras diferenciadas, como a busca de uma representação caricaturada do homem interiorano, jocosa, distante das transformações do mundo moderno que invadiam a cidade. A "atualidade" da ilustração é outro ponto que merece destaque. Em outras palavras, a figura do matuto, publicada em 1905, assemelha-se à maneira como é representado hoje em dia quando o assunto envolve festas juninas na cidade - bigode e cavanhaque pintados, roupa de xadrez, chapéu de palha, cachimbo... 
A caricatura transmite também a ideia de distanciamento, espacial e temporal, de um Brasil rural, vivo somente nas lembranças dos mais velhos e na decoração de motivos ditos exóticos de algumas datas festivas, como o São João, momento no qual a cidade se interioriza, mesmo que temporariamente. A festa, nesse sentido, abre espaço para a representação do matuto como a imagem de um homem que pertencia ao campo.

Fica então a questão: o campo de fato está distante da cidade ou a cidade e o campo não se desligaram ainda por completo? Se considerarmos que em 1905 o Brasil era eminentemente rural, talvez fosse o caso de falar de um país rural que não dialogava com os projetos de modernidade então em curso nos centros urbanos, alegando que os fluxos que constituíam a cidade traziam outros movimentos, valores e produtos que ela não produzia no seu interior. Apesar de que, nesse período, a vida no campo, de certa forma, moderniza-se, especialmente pela implantação de uma malha ferroviária que abrevia as distâncias entre campo e cidade.

Uma rede de significados em torno da celebração se estabelece na cidade por meio de discursos orquestrados pela imprensa, a qual reforça a tessitura de diferentes sentidos para a festa, entre os quais o momento de reaproximação do tempo perdido, que somente é possível de ser vivenciado no tempo exato de comemoração do São João selecionado institucionalmente, num período de dois ou quatro dias.

"O que nós vê na capitá" e "Eita Recife bão" são expressões que reforçam o estereótipo dos moradores interioranos como sendo iletrados, que preservam um sotaque ruralizado, recheado de expressões do português arcaico, quase não mais falado na cidade. Na capital, essas expressões destoam dos flirts, dos footing, de ser chic ou smart, conforme se falava nas ruas da área central de Recife, transformado com amplas avenidas, praças e estátuas importadas da Europa.

A essa transformação do espaço público, assistia-se ao desmembramento entre o campo e a cidade: sociedades antagônicas, cujas práticas do campo eram condenadas pelo urbano, maculando a imagem civilizada da sociedade aburguesada que desfrutava das áreas centrais da cidade. Uma das reações contra o campo centrava-se, justamente, na figura do matuto, visto como indolente, preguiçoso, desviado do novo parâmetro acelerado da vida, tal como retrata Monteiro Lobato na figura do Jeca Tatu, personagem símbolo do matuto na literatura brasileira.

A esse personagem de pés descalços, com aspecto doentil e desolado, opunha-se o homem robusto da cidade, de hábitos elegantes, bem vestido, trocando a companhia dos cães e de outros bichos da roça, pela agitação dos carros, dos pedestres, das 
conversas calorosas nos cafés em fins de tarde. A figura do Jeca Tatu foi usada pela campanha publicitária do medicamento Biotônico Fontoura, a partir dos anos 1920, período no qual o país vivenciava uma luta contra a febre tifoide, a varíola, a desnutrição, a anemia, entre outras endemias que atravessaram o século XIX e se instalaram na cidade ainda com vastas áreas úmidas, sem asfalto e pantanosas.

Nesse cenário, com focos de insalubridade, as autoridades políticas lançaram uma intensa campanha de saúde pública voltada para a população de pobres, doentes e analfabetos, e distribuíam nas escolas, da cidade ao interior, um instrumento pedagógico chamado Almanaque do Biotônico Fontoura, em circulação no país até o início dos anos 1980 .

Segundo a pesquisadora Fátima Faleiros Lopes, o Almanaque, em diálogo com os objetivos políticos da época, estava inserido "no projeto de reforma e de civilização do Estado brasileiro no início do século XX, com vistas à formação de pessoas sadias, moralmente aptas e úteis para a construção do progresso" (LOPES, 2002, p. 21).

Assim, a figura do matuto surge associada a uma imagem contrária ao progresso, cristalizada pelo discurso do homem urbano como alheia aos padrões da sociedade do novo século, condenado por hábitos antigos, preguiçosos, podendo macular a imagem de uma sociedade cosmopolita em desenvolvimento. Um exemplo a não ser seguido pela população das grandes capitais brasileiras (SEVCENKO, 2003).

Aos poucos, esse tipo popular, comumente visto nas ruas do Recife vai se interiorizando cada vez mais, voltando à cidade sazonalmente, nos festejos juninos. Em outras palavras, cria-se uma nova memória de algo que já existia. Esse discurso construído do matuto soma-se ao tom lúdico que a imprensa atribuía à festa, sempre associada a brincadeiras infantis e situações que remetiam ao passado repleto de momentos considerados inofensivos.

Desse período datam os anúncios de venda dos livros de sorte na imprensa, muito comuns nos primeiros anos do século XX e não mais encontrados nos registros documentais a partir da segunda década. Segundo o folclorista Câmara Cascudo, eram "livros de versos numerados, em quadrinhas, contendo profecias humorísticas para rapazes e moças durante a festa de São João" (CASCUDO, 2001, p. 645).

As pesquisas revelaram uma complexidade bem maior do que a utilizada por Câmara Cascudo para descrever as publicações. Segundo a imprensa, anedotas, jogos, feitiçarias amorosas, mágicas, receitas, contos, sonetos de poetas pernambucanos, duetos, cançonetas, monólogos, modinhas, lundus, trovas populares, fados portugueses 
e até mesmo valsa para piano formavam o conteúdo desses livros. Os anúncios apareciam próximos aos chamados para as festas e as procissões religiosas dos santos da época e os nomes eram também bastante convidativos: o cabeção, a espiga, o estrondamundo, a sogra, a limalha, a panela do feitiço, pimpão, a serpentina, Urucubaca, Malmequer, entre outros.

Os livros eram comercializados em agências jornalísticas, casas de fogos, livrarias e armarinhos. Algumas pessoas, ao fazer uso e querendo se desfazer da publicação, anunciavam nos jornais a venda do livro. Em geral, tinha preços que variavam entre 500\$00 (quinhentos réis) e 1\$000 (mil réis), fator determinado pelo número de páginas. O Malmequer, por exemplo, tinha quase cem páginas e uma "capa nitidamente imprensa e ornada de um bem acabado art noveau, de Guapy" (Jornal Pequeno, Recife, 23 junho de 1904).

Os livros eram usados de forma individual ou coletiva e compartilhavam com os diferentes segmentos sociais a vivência da festa. Eles respondiam às continuidades das tradições do São João, que faziam do espaço urbano moderno o cenário de preservação desse simbolismo.

A vivência dos livros de sorte era representada pela imprensa e na literatura como momentos familiares, garantindo o tom pacífico e inofensivo da celebração. Assim, Mello Moraes Filho descreve: "as moças da corte, na elegante varanda, brincavam com fogos ou, sentadas à mesa de jantar, deitavam dados, liam as quadrinhas da sorte, prorrompiam em gargalhadas, às predições do destino" (MORAIS FILHO, 1946, p. 116).

Os possíveis benefícios que os livros podiam proporcionar também eram descritos pela imprensa e funcionavam como convite aos compradores. O Estrondamundo, por exemplo, era "infalível para ganhar fortuna no jogo de quanto bicho há” (Jornal Pequeno, Recife, 25 junho de 1902). Outras mudanças de vida também eram anunciadas, como: "obter o que deseja, alcançar posições, alcançar o que aspira, ter fortuna, ter sorte, mudar de lugar, ganhar o inquérito" (Jornal Pequeno, Recife, 25 junho de 1902).

As fontes também apresentaram que alguns livros ofereciam prêmios em dinheiro para os compradores. Um estímulo a mais na hora de escolher qual livro levaria para casa. “A Sogra. Magnífico livro de sortes. Prêmio em dinheiro. 100\$00. Comprem! Comprem!", anunciava o jornal Pequeno (26 de junho de 1905). 
Os anúncios dos livros de sorte apareciam, em geral, na mesma página onde se encontram as notas sobre a vida dos santos. Uma forma de associar a prática do "jogo" com o santo homenageado. Os textos dedicados às biografias dos santos, também conhecidos como hagiográficos, eram publicados nos dias oficialmente reconhecidos pela Igreja e registravam diversas passagens bíblicas, como forma de aproximar a divindade dos fieis. Um dos exemplos que destacamos é o fragmento que ressalta a peregrinação do humilde pescador da Galileia, o apóstolo Pedro, a Roma, “capital do mundo", com a missão de "derrubar os obstáculos e solapar o paganismo, inoculando no espírito de todos as verdades reveladas pelo Divino Mestre" (Jornal do Recife, Recife, 29 junho de 1901).

Outras hagiografias se seguem, a exemplo da portaria de 13 de setembro de 1685, que concedeu a Santo Antônio, por ordem do governador João de Souto Maior:

[...] o assento de praça, para seguir na guerra de Palmares e proteger as armas reais na conquista desse quilombo. [...] em 30 de abril de 1717, expediu o Conselho Ultramarino uma provisão, elevando-o no posto de tenente da fortaleza do Buraco, a que promoveu o governador D. Lourenço de Almeida, vencendo o saldo mensal de $2 \$ 700$ réis (Jornal do Recife, Recife, 13 junho de 1905).

Tendo se passado quinze anos do novo século, na seção "Alma Religiosa", o Diário de Pernambuco, em meio a notícias de missas e batizados, continuava apresentando ao leitor histórias de vida dos santos, a exemplo da saga de São João, que:

No ano 20, no império de Tibério, dirigiu-se às margens do Jordão a fim de pregar a penitência. Jesus foi então pedir-lhe o batismo. Designou-o São João ao povo como o Messias, o Cordeiro de Deus. Passando a corte de Herodes Antipas, tetrarca da Galilea, verificou-lhe os escândalos com a sua palavra candente de indignação. Herodes não ousou ordenar a sua morte. Mandou, porém, encarcerá-lo na fortaleza de Machefus. Mas tinha Salomé, esposa incestuosa do tetrarca. A princesa para se livrar de São João, que lhe repetira o imbriro amor, obteve de Herodes a morte do inocente prisioneiro. São João foi decapitado, sendo sua cabeça enviada num prato a Salomé. E a princesa com ela dançou perante a corte (Diário de Pernambuco, Recife, 24 de junho de 1923).

Essa tragédia bíblica, que motivou notas especiais de periódicos durante o mês de junho em diferentes épocas, chegou a ser exibida como projeção, no dia 24 de junho de 1913, dentro da programação do Theatro Moderno, localizado na praça da Concórdia, centro do Recife.

As biografias dos santos seguiram como pauta da imprensa no decorrer de toda a década de 1920, dividindo espaço com notas de desencantos cada vez mais comuns no tocante aos rumos que as celebrações vinham tomando. No Diário de Pernambuco de 
24 de junho de 1926, a história do precursor, filho de Zacarias e Izabel, nascido na tribo de Judá e falecido na Palestina, cedeu algumas linhas para o registro do sentimento de desolação que assolava grande parcela dos moradores da cidade:

Herdeiros dos costumes da velha gente lusitana, mantemos também carinhosamente, o culto de São João. Não se pode, entretanto, simular que ele tem muito decaído de seu primitivo esplendor. E que se vai infelizmente perdendo a singeleza e ingênua tradição. Ainda no interior é celebrada a festa do Batista com as fogueiras, com os rojões e as ronqueiras, com as sortes e as adivinhações, os descantos do violão, o milho assado no braseiro, a canjica. Nos meios mais populosos e adiantados, onde as tradições vão desaparecendo aos poucos, o culto de São João vai em declínio. A Igreja Católica chegou até mesmo a suprimir o santificado dia (Diário de Pernambuco, Recife, 24 junho de 1926).

As críticas às mudanças que a vida social na capital estava passando com a modernização faziam-se presentes no cotidiano da imprensa, cujos textos transformados em crônicas e poemas constituíam os principais veículos de circulação das ideias de intelectuais, escritores e poetas que queriam conquistar um espaço no mundo das letras. Era um campo também para fazer-se perceber na sociedade, lugar de prestígio social e fundamental para se afirmarem economicamente diante do novo cenário que cada vez mais burocratizava o Estado.

Para esses intelectuais, era necessário estar ligado a algum órgão de imprensa ou escrever como colaborador de algum periódico para se fazer notar e respeitar diante da sociedade (MOURA, 2012). O jornalista Souza Barros chega a afirmar que "Não se podia admitir o intelectual se ele não aparecesse na imprensa numa atividade qualquer, nela trabalhando diretamente ou levando como colaborador as suas produções" (BARROS, 1972, p. 176).

Frente essa perspectiva, na década de 1920, o trabalho da imprensa encontravase cada vez mais especializado. No corpo de profissionais de um jornal ou revista era comum encontrar no seu quadro de colaboradores, cronistas, desenhistas, revisores, redatores, editores, entre outros profissionais que dividiam diariamente as atividades para que as informações chegassem o mais rápido possível aos olhos dos leitores (SILVA, 2009).

Nesse contexto foi encontrada a poesia "Cantigas de São João", do pernambucano Austriclínio Ferreira Quirino, popularmente conhecido pelo pseudônimo de Austro Costa. No texto, o escritor povoa de interrogações a festa de São João vivenciada por ele na infância: a fogueira, o milho assado, os seresteiros, os busca-pés, mas lamenta a passagem do tempo, rápida "como bolha de sabão". 


\section{Cantigas de São João}

Doce São João de minha infância que é de ti feito, o meu São João onde a poesia, onde a fragância

da "capelinha de melão"?

Onde a ruidosa alacridade de quando vinhas tu, então, bordando em minha ingenuidade

florões de enlevo e ilusão?

Onde a fogueira e o milho assando? teus seresteiros... onde estão? e os "busca-pés" cabriolando sinistramente, pelo chão?

E os meus balões?... Eu - tão menino (Bem que me lembro! Que emoção!)

E já, tão cedo! O meu destino a se queimar ... como um balão

Onde as moçoilas casadoiras jogando, às sortes, a ambição? (Acaso viu, como desdoeiras, As vezes, tanto coração!)

São João, que é feito disso tudo Que amei em tempos que lá vão Tudo passou ... já não me iludo! Tudo foi bolha de sabão?...

Tudo passou, mas a saudade Chama de eviternal cisrão Arde na minha soledade Tudo passou ... só ela... não!

São João, São João, que nostalgia Chora em meus olhos! Aflição...

Lembrar ... sentir (que noite fria) Que hoje és bem outro, ó meu São João! (Diário de Pernambuco. Recife 23 junho de 1923)

Austro Costa foi um dos principais nomes da imprensa pernambucana da década de 1920. Contribuiu com seus escritos para diversos periódicos do estado, "desde os da grande imprensa de circulação diária aos órgãos de grupos carnavalescos e de humor, passando pela Revista do Norte, símbolo maior do movimento cultural inovador de matriz pernambucana: Jornal do Recife, Diário de Pernambuco, A Pilhéria, Pra Você, e tantos outros" (GASPAR, 2009, p. 3). 
O São João, ou melhor, as formas de expressão cultural dos populares não eram o objeto de discussão desse intelectual. Fazendo uso de diferentes pseudônimos (João da Rua Nova, Chrispim Fialho, João Queremista, João-do-Moka, Afêquirino, Alcedo Tryste, Silvio d'Almeida, Fra-Diávolo, Tybaldo d'Alcazão, Tritão e X), o escritor se dedicava a temas relacionados ao comportamento social que tomava conta das ruas e de outros espaços de sociabilidade de uma cidade moderna. O universo da moda muito chamou a sua atenção, principalmente os elegantes passeios das damas na Rua Nova principal vitrine dos artigos de luxo da capital. É de sua autoria a coluna no Diário de Pernambuco: do flirt, do footing da Rua Nova, assinada sob o pseudônimo de João da Rua Nova. Outros lugares recém-inaugurados no Recife dos anos 1920, como Boa Viagem, ou considerados como ponto de encontro das moças elegantes, a exemplo do Carmo em Olinda, também tiveram destaque nos registros de Austro Costa.

Do mesmo modo que encontramos em Austro Costa produções pontuais sobre os festejos juninos, localizamos nos periódicos da época outros escritos que merecem destaque: o poema O São João do meu passado, de Durval Cesar, na Revista da Cidade de 1926; uma nota assinada por um escritor chamado Van sobre um evento na Associação Pernambucana de Atletismo, intitulado Em torno de uma festa caipira; uma crônica, Lembranças de São João, por Paulo Malta Filho e o Poema de São João, de Álvaro Lyns, todos publicados na Revista Pra Você de 1930.

Alguns textos aparecem sem assinatura, a exemplo do editorial da Revista da Cidade de 18 de junho de 1927. Esta publicação aponta que o tema da celebração se resumiu, exclusivamente, no texto de abertura do periódico, sem nenhuma outra menção à data no corpo do documento. Situações como esta foram encontradas em outros números, até mesmo de outras publicações, que apresentavam o tema isoladamente, sem nenhum texto complementar, desvinculado de um contexto.

Diferentes periódicos, por exemplo, faziam alusão ao tema somente na ilustração que estampava a capa do número ou quando publicava alguma fotografia solta de alguma comemoração num clube da cidade entre as páginas (Revista da Cidade, Recife, $\mathrm{n}^{\mathrm{o}} .6$, 1926). As ilustrações das capas dos periódicos que circulavam na cidade, quando abordavam o tema em algumas edições, constituem bons exemplos sobre esse tipo de situação (Figura 3 e Figura 4).

Revista Escritas do Tempo - v. 1, n. 2, jul-out/2019 - p. 52-74 
DOI: 10.47694/issn.2674-7758.v1.i2.2019.5274

Figura 3. Capa com desenho de Villars da Revista da Cidade. 
DOI: 10.47694/issn.2674-7758.v1.i2.2019.5274

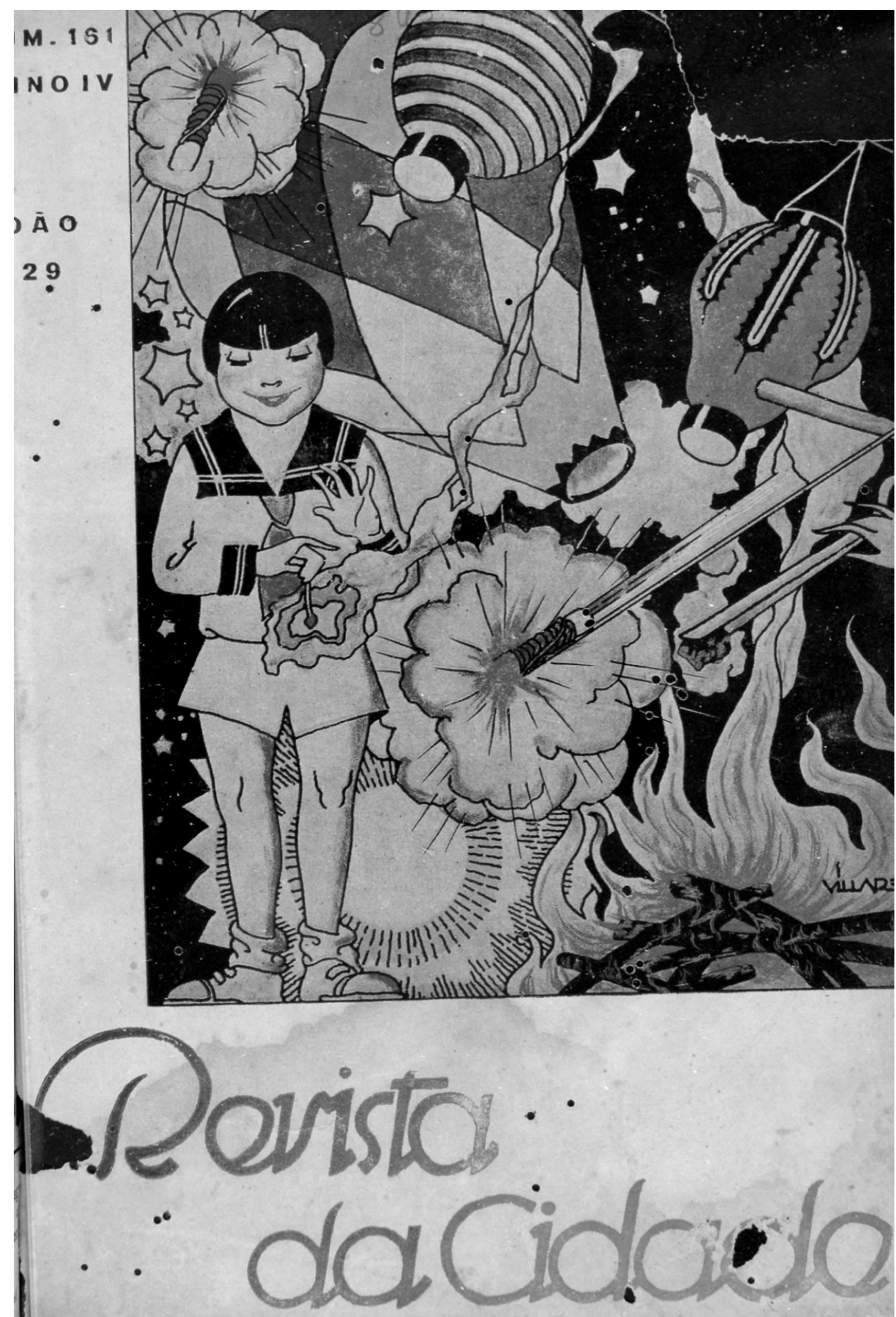

Fonte: Recife, 22 jun. 1929, n 161 . Acervo da Fundaj. 
Figura 4. Capa com desenho de Jota Canulp da Revista.

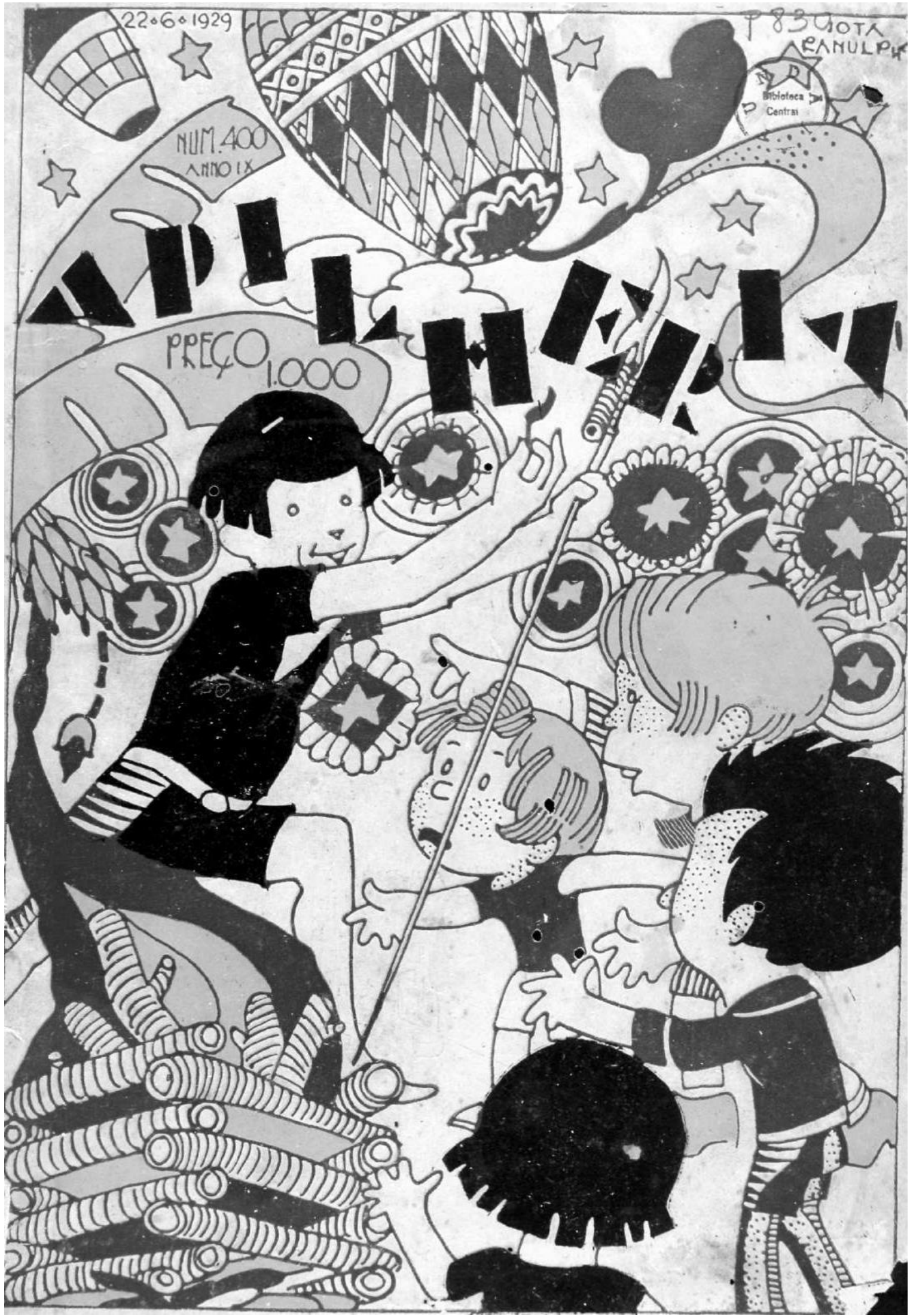

Fonte: A Pilhéria, 22 jun. de 1929, nº 400. Ano IX. Acervo Fundaj. 
É perceptível nas imagens o uso dos balões e dos fogos de artifício nas festas de junho. Talvez, de todos os símbolos da época, as brincadeiras com fogos são as que mais ficaram nas lembranças dos intelectuais e, por isso, aparecem com mais frequência nos registros encontrados sobre o assunto.

A cultura dos fogos no Brasil é uma prática apreendida pelos colonos brasileiros dos momentos de comemoração portuguesa em datas festivas. Essa invenção chinesa é um "complemento indispensável nas festividades religiosas do Brasil, já no final do século XVII" (CASCUDO, 2001, p. 239). Sinalizador de significados múltiplos, os fogos exercem funções de anunciar o início, o apogeu e o término de uma solenidade; nascimentos, casamentos, vitórias.

No período junino, constituem um dos elementos principais do cenário da festa. Tiros de cores que iluminam o céu. Cachoeiras de fogo que caem pelos ares nos telhados dos sobrados e igrejas, nas ruas, nos quintais e nas calçadas animadamente preenchidos de crianças, jovens, idosos e adultos - gentes das mais diversas procedências, credos e valores. "Os festejantes soltavam girândolas e gritavam Viva São João! - cujos ecos iam morrer nas florestas. Muitos respondiam cantando São João está dormindo, não acorda não!”, recorda Mello Moraes Filho (MORAIS FILHO, 1946, p. 114). A pomposa procissão de São Pedro, em junho de 1929, terminou com "um bem confeccionado fogos de artifício", registra um dos jornais de circulação no Recife (Diário de Pernambuco, Recife, 29 de junho de 1929).

$\mathrm{O}$ folclorista rememora que nessa época do ano as gavetas e as mesas das fazendas ficavam atravancadas de "rodinhas, pistolas, foguetes, busca-pés, chuveiros, rojões, cartas de bichas, girassóis, traques de sete estouros, bombas e uma diversidade enfadonha de fogos" (MORAIS FILHO, 1946, p. 111). De todos esses, o mais popular era o busca-pé. O pesquisador Câmara Cascudo diz que esse tipo de "rojão, horizontal e rasante" era utilizado nas brincadeiras e diversões de meninos e rapazes dedicados a "espavorir gente velha, debandar reuniões graves, espantar dançadores, tornar intransitáveis as ruas, com verdadeiras batalhas de uma calçada para a outra" (CASCUDO, 2001, p. 82). Foram os busca-pés, motivos de muitas risadas de rapazes que se divertiam vendo as descomposturas das vítimas, que saíam pulando e correndo em descompasso fugindo dos estouros e acidentes no escurecer das noites de São João (MORAIS FILHO, 1946, p. 114). 
Certamente, esse tipo de fogos era um dos mais populares da festa, talvez um dos mais baratos e, por isso, um dos mais consumidos por toda a população. Pereira da Costa registra que, a seu modo, "a gente do miuçalho" enfeitava-se de capelas de flores e folhas, soltavam bombas e disparavam ronqueiras e bacamartes" (COSTA, 2004, p. 199). Aqueles que não podiam comprar fogos "brincavam em torno das fogueiras, ora nas calçadas, soprando brasas, tições de angico."

Mas será que todos os participantes da festa viam essa prática como inofensiva e lúdica, associada à diversão dos festeiros? A historiadora Martha Abreu (2009), em pesquisas sobre as políticas de licença de festas da Câmara do Rio de Janeiro informa que, em 1830, já existiam medidas de controle sobre o uso dos fogos. Entre as restrições assinadas pela Câmara, a autora destaca a necessidade de um pedido de permissão para soltar fogos com a possibilidade de negação e a prática de ações cerceadoras e punitivas para aqueles que infligirem as normas. Outro ponto foi a permissão para execução de fogos em praças e ruas de 60 palmos de largura sem a possibilidade de haver riscos ou danos (ABREU, 2009, p. 250-255). Essas restrições atravessaram o século XIX e chegaram até as primeiras décadas do século XX com o mesmo propósito preventivo e normatizador.

Em Pernambuco, em 13 de junho de 1910, a Repartição Central da Polícia publicou o seguinte comunicado do secretário Joaquim Agrippino de Mendonça Simões:

De acordo com o código de posturas municipais, fica proibido dentro da cidade o uso de ronqueiras, bombas e fogo solto (busca-pés); os infratores serão multados em 30\$000 e no dobro pela reincidência (art. 5, título 3, cap. 4). Fica igualmente proibido o costume de se fazerem fogueiras nesta cidade, por ocasião das festividades de Santo Antônio, São João e São Pedro e outros quaisquer dias. Os contraventores pagarão a multa de $10 \$ 000$ e o dobro na reincidência (art. 6, tit. 4, cap.1). Fica proibido o uso de fogo do ar solto na cidade, que não for em girândola pelo sistema Morel, precedendo licença. Os infratores pagarão a multa de $20 \$ 000$ e o dobro na reincidência (artigo 4, tit. 4, cap. 5). Não se poderá soltar fogo algum, senão em pátios espaçosos ou quintais, nunca em lugar de adjunto. Os infratores incorrerão na multa de $10 \$ 000$ (art. 6, cap. e títulos citados). Não é permitido dentro do município dar tiros ou disparar armas de fogo a qualquer hora do dia ou da noite. As multas serão acrescidas em 20 por cento de adicionais (Jornal Pequeno, Recife, 13 junho de 1910).

Essas medidas proibitivas transpassaram as duas primeiras décadas do século XX e chegaram ao Estado Novo, conforme foi identificado nas medidas de normatização da festa assinadas pelo Dr. Etelvino Lins, Secretário de Segurança Pública 
do Estado, em 02 de junho de 1938. De acordo com o documento, a portaria proibia o uso de fogos e a sua fabricação na cidade. Segundo o registro, a autoridade,

no interesse do bem público, resolve proibir o fabrico, a venda e o uso dos seguintes fogos: traques grandes triangulares, bombas de pavio, buscapés de estouro, bombas transvalianas, limalhas de estouro, ronqueiras em geral, foguetes e foguetões no perímetro urbano da cidade (Folha de Manhã, Recife, 03 de junho de 1938).

Esse tipo de regulamentação visava à manutenção da ordem pública e ao mesmo tempo tinha um sentido de alertar a população para as implicações daqueles que não cumprissem a lei. O título da nota ("Fogos Proibidos") e o teor das palavras empregadas, não permite a interpretação de um significado preventivo, alertando para os cuidados que a população deveria tomar.

A medida de lei publicada no início do mês mais propício à utilização de fogos parecia não intimidar a população. As notícias de acidentes veiculadas com frequência na coluna "O Dia Policial" do jornal Folha da Manhã, ilustram esses momentos de desvios do sistema. No dia após as comemorações oficiais de São João, 25 de junho, cinco casos envolvendo acidentes com fogos foram noticiados pela imprensa: "Perdeu os dedos da mão" (25/06/1938), "sofreu queimaduras" (25/06/1938), “um menor vítima de uma explosão" (25/06/1938), "fabricando bombas foi mal sucedido" (25/06/1938), “a bomba lhe explodiu na mão" (25/06/1938). Nos anos seguintes, os acidentes com fogos se repetiram na mesma proporção e gravidade.

Os fogueteiros fabricavam os fogos na clandestinidade, nos lugares mais afastados dos centros urbanos, em geral nos subúrbios, em horários de pouco movimento nas ruas. Esse silenciamento, ou melhor, isolamento, era um dos fatores que dificultava o socorro da vítima no momento dos acidentes.

Em geral, como forma de punição desses acidentes, a polícia registrava o caso na delegacia mais próxima do ocorrido, abrindo inquérito para os envolvidos. Não foi identificada na documentação analisada nenhuma punição, como pagamento de multas ou prisões, por exemplo, por parte dos envolvidos.

No entanto, um fato chama atenção nas pesquisas nos jornais: os "fogos de luxo" permitidos de serem utilizados pela elite nos "soirées" e outras grandes festas realizadas nos clubes da cidade. Na programação dos festejos juninos do Clube Internacional do Recife, a Diretoria do espaço deliberou que, no dia 24, "na matinée infantil, das $15 \mathrm{~h}$ às 19 horas, haveria sorteio de fogos de luxo entre a guryzada." A nota continua informando que nas noites dos dias 23 e 28 , iria exibir "fogos de artifício de grande 
efeito" e o "início das festividades seria marcado com uma gyrandola (Folha da Manhã, Recife, 05 de junho de 1938)." Que fogos de luxo são esses permitidos de serem utilizados inclusive por crianças? A imprensa não revela os tipos e não revela nomes, formas, efeitos e cores. Tomando de empréstimo os relatos de memória da professora Andréa Gondim Fernandes, sobre as festas de São João no engenho em Pedregulho (Goiana-PE), as crianças recebiam traques de massa e estrelinhas com seus "chuviscos e lágrimas que davam à noite um colorido fantasmagórico" (FERNANDES, 1986, p. 224). O escritor Célio Meira registrou que "as senhoras, tremendo o braço, soltavam pistolas multicores. E, de braço firme, empunhavam craveiros" (Folha da Manhã, Recife, 23 de junho de 1940).

Estabelecendo uma relação com a portaria que proíbe o uso de fogos, inferimos que a segregação que existe do ponto de vista do lugar social dos sujeitos que participam e vivenciam as festividades sanjoanescas, o mesmo acontece com o tipo de brincadeira e as formas de diversão que protagonizam. Os busca-pés, as bombas de pavio e os foguetes não fazem parte do "kit" de fogos comprado pelos adultos da elite para as crianças e os jovens se divertirem nas noites "tão brasileiras de fogueiras". A normatização existe no sentido de limitar a participação dos menos favorecidos na festa, entretanto, as táticas criadas para burlar as proibições permitem que essa festa se reinvente em cada lugar, cada grupo social e cada nova temporalidade.

\section{Considerações Finais}

O conjunto de imagens que se tece em torno dos festejos juninos atribui novos significados à vivência da celebração na cidade, motivo que nos leva a concordar com Raimundo Arrais, quando afirma que "um espaço não tem uma natureza cristalizada. Seus significados derivam dos investimentos simbólicos feitos sobre ele, por meio de rituais promovidos pelo Estado ou certos grupos sociais" (ARRAIS, 2004, p. 15).

Com base nesse pensamento, que reforça a inexistência de espaços sem as práticas que lhe conferem sentido, nesse estudo, buscamos apresentar o São João do Recife integrado às práticas cotidianas dos indivíduos, com sinais claros que definem a cidade e sua gente, e não como uma realidade oposta a este universo (CERTEAU, 2008, p. 39-40).

Desse modo, torna-se mais fácil perceber a teia de relações sociais que cerca o fenômeno estudado, possibilitando não elaborar um trabalho meramente pelo ângulo descritivo, uma vez que estamos diante de um conjunto de ações e atividades que 
reverberam para além das fronteiras da espetacularização. Uma prática que interage, direciona e transforma o cotidiano de diferentes grupos sociais, formados na sua maioria por comerciantes, artesãos, músicos, jornaleiros, auxiliar de comércio, biscateiros, desempregados, entre outros personagens de diferentes classes sociais.

Essa maneira de enxergar a festa, como ação coletiva, ultrapassa o sentido de válvula de escape atribuído por alguns estudiosos. Embora seja possível considerar que as ilustrações das capas dos periódicos apresentam a festa de forma lúdica, o teor de algumas reportagens dos jornais chama a atenção do leitor para temas que se aproximam da realidade, a exemplo dos altos índices de acidentes provocados pelos fogos de artifício.

O conteúdo dos documentos da imprensa sinaliza para o entendimento de como foram construídas as representações das festas joaninas nos discursos dos homens da cidade. Elas constroem elos com o passado rural, transfigurando o cenário urbano com símbolos e personagens que remetem à vida nas fazendas e nos engenhos. Os materiais veiculados ultrapassam o ato de divulgar o São João. Eles vão além, difundindo traduções de pensamentos, opiniões, imagens e visões sobre como as festas juninas são e devem acontecer. Segundo Valdir Morigi,

As significações infiltram-se nas representações coletivas, passando a compor o imaginário do lugar e das pessoas que ali vivem. Isso traz implicações de ordem simbólica, interferindo nas construções do imaginário social e podendo criar noções regionalizadas na maneira de se ver e de ser visto diante do olhar do outro, no qual estão em jogo as construções de sentido e as formas indenitárias (MORIGI, 2007, p. 110).

As festas juninas, nesse sentido, eram representadas a partir de diferentes vieses pela imprensa. Através da veiculação de temas diversos foi possível uma aproximação maior com o cotidiano da cidade, permitindo familiarizar-se com o meio social em que convivia sua gente. A historicidade das festas juninas se expressa justamente no modo com que cada grupo social se encontra para celebrar a época. Posturas regulamentadoras e punitivas, reflexões sobre mudanças e permanências, campanhas preventivas, modismos, entre outros assuntos, que aparentemente negligenciáveis no campo historiográfico fornecem indicações relevantes para novos desdobramentos e projeções do tema.

\section{Referências}

ARRAIS, Raimundo. O pântano e o riacho: a formação do espaço público no Recife do século XIX. São Paulo: Humanitas /FFLCH/USP, 2004. 
BARROS, Souza. A década de 20 em Pernambuco: uma interpretação. Rio de Janeiro, 1972.

CASCUDO, Luís da Câmara. Dicionário do Folclore Brasileiro. 10 ${ }^{a}$ ed. São Paulo: Global, 2001.

CERTEAU, Michel de. A invenção do cotidiano: morar, cozinhar. $7^{\mathrm{a}}$ ed. Petrópolis: Vozes, 2008.

COSTA, Francisco Augusto Pereira da. Folk-lore pernambucano: subsídios para a história da poesia popular em Pernmbuco. 2. Ed. Recife: CEPE, 2004.

DIÁRIO DE PERNAMBUCO. Recife, 24 de junho de 1923.

DIÁRIO DE PERNAMBUCO. Recife 23 junho de 1923.

DIÁRIO DE PERNAMBUCO. Recife, 24 junho de 1926.

DIÁRIO DE PERNAMBUCO, Recife, 29 de junho de 1929.

FERNANDES, Andréa Corrêa Gondim. Velhos Engenhos de Minha Terra. Editora ASA: Pernambuco, 1986.

FOLHA DE MANHÃ, Recife, 03 de junho de 1938.

FOLHA DA MANHÃ, Recife, 05 de junho de 1938.

FOLHA DA MANHÃ, Recife 24 junho de 1939.

FOLHA DA MANHÃ, Recife, 23 de junho de 1940.

GASPAR, Lúcia. BARBOSA, Virgínia. Austro-Costa: 110 anos em revista. Recife: Fundação Joaquim Nabuco, 2009.

JORNAL DO RECIFE, Recife, 29 junho de 1901.

JORNAL DO RECIFE, Recife, 13 junho de 1905.

JORNAL PEQUENO, Recife, 25 junho de 1902.

JORNAL PEQUENO, Recife, 23 junho de 1904.

JORNAL PEQUENO, Recife, 21 junho de 1905.

JORNAL PEQUENO, Recife, 26 junho de 1905.

JORNAL PEQUENO, Recife, 13 junho de 1910. 
LOPES, Fátima Faleiros. Memória, História, Educação: trilhas sugeridas por um “Almanaque". Dissertação (Mestrado em Educação), Universidade Estadual de Campinas, Campinas, SP, 2002.

MORAES FILHO, Mello. Festas e Tradições Populares do Brasil. 3. ed. Rio de Janeiro: F. Briguiet \& Cia, 1946.

MOURA, Carlos André Silva de. Fé, Saber e Poder: os intelectuais entre a Restauração Católica e a política no Recife (1930-1937). Recife: Prefeitura da Cidade do Recife, 2012.

MORIGI, Valdir José. Narrativas do Encantamento: o maior São João do mundo, mídia e cultura regional. Porto Alegre: Armazém Digital, 2007.

O SÃO JOÃO DOS GAZETEIROS. Revista da Cidade, Recife, n. 6, 1926.

RABELlO, Evandro. Memórias da folia: o Carnaval do Recife pelos olhos da imprensa. Recife: Funcultura, 2004.

REVISTA A PILHÉRIA. Recife, 1925, n. 196, p. 32.

REVISTA A PILHÉRIA. Recife, 1925, n. 196, p. 14.

REZENDE, Antônio Paulo de Morais. (Des)encantos modernos. Histórias da Cidade do Recife na Década de 20. Recife: FUNDARPE, 1997.

SANTOS, Mário Ribeiro dos. Trombones, tambores, repiques e ganzás: a festa das agremiações carnavalescas nas ruas do Recife. Recife: SESC, 2010.

SEVCENKO, Nicolau. Literatura como Missão. Tensões sociais e criação cultural na Primeira República.2. ed. São Paulo: Companhia das Letras, 2003.

SILVA, Lucas Victor da. O Carnaval na cadência dos sentidos: uma história sobre as representações das folias do Recife entre 1910 e 1940. Tese (Doutorado em História), Universidade Federal de Pernambuco, Recife, PE, 2009. 